\title{
Vitamin D deficiency and insufficiency among US adults: prevalence, predictors and clinical implications
}

\author{
Xuefeng Liu ${ }^{1,2 *}$, Ana Baylin ${ }^{3}$ and Phillip D. Levy ${ }^{4}$ \\ ${ }^{1}$ Department of Systems, Population, and Leadership, University of Michigan School of Nursing, Ann Arbor, MI 48109, USA \\ ${ }^{2}$ Frankel Cardiovascular Center, University of Michigan School of Medicine, Ann Arbor, MI 48109, USA \\ ${ }^{3}$ Departments of Nutritional Sciences and Epidemiology, University of Michigan School of Public Health, Ann Arbor, MI 48109, USA \\ ${ }^{4}$ Department of Emergency Medicine and Cardiovascular Research Institute, Wayne State University School of Medicine, \\ Detroit, MI 48202, USA
}

(Submitted 8 June 2017 - Final revision received 21 November 2017 - Accepted 11 December 2017)

\section{Abstract}

Vitamin D deficiency (VDD) and insufficiency (VDI) are increasing at a global level, and they are associated with increased risk of various diseases. However, little information is available on the prevalence and predictors of VDD and VDI in a representative population of US adults. Serum 25-hydroxyvitamin D (25(OH)D) measurements were collected from 26010 adults aged $\geq 18$ years from the National Health and Nutrition Examination Survey (NHANES) 2001-2010. Using thresholds recommended by the Endocrine Society, VDD was defined as $25(\mathrm{OH}) \mathrm{D}<50 \mathrm{nmol} / 1$ and VDI as $50 \leq 25(\mathrm{OH}) \mathrm{D}<75 \mathrm{nmol} / \mathrm{l}$. Weighted multinomial log-binomial regression was conducted to estimate prevalence ratios of VDD and VDI. The prevalences of VDD and VDI in 2001-2010 were 28.9 and 41.4\%, respectively. Adults who were black, less educated, poor, obese, current smokers, physically inactive and infrequent milk consumers had a higher prevalence of VDD. After adjustment for other potential predictors, obese adults showed 3.09 times higher prevalence of VDD and 1.80 times higher prevalence of VDI than non-obese adults. Physically inactive adults had 2.00 and 1.36 times higher prevalence of VDD and VDI than active peers. Compared with frequent consumers, rare consumers of milk had 2.44 and 1.25 times higher prevalence of VDD and VDI, respectively. Current alcohol drinkers had $38 \%$ lower prevalence of VDD than non-drinkers. Awareness of the high prevalence of VDD and VDI among US adults and related predictors could inform behavioural and dietary strategies for preventing VDD and monitoring VDI, especially in old, black, obese and inactive individuals who report rare consumption of milk.

Keywords: Vitamin D deficiency: Vitamin D insufficiency: Prevalences: Predictors: Adults: National Health and Nutrition Examination Survey

Humans obtain vitamin D from exposure to sunlight, diet and dietary supplements ${ }^{(1,2)}$. Although there is no consensus on optimal 25-hydroxyvitamin D (25(OH)D) concentrations as measured in serum, vitamin D deficiency (VDD) is commonly defined as a $25(\mathrm{OH}) \mathrm{D}$ concentration of $<50 \mathrm{nmol} / 1(20 \mathrm{ng} / \mathrm{ml})^{(1-4)}$. This cut-off is the point where parathyroid hormone (PTH) starts to rise, which is the physiological definition of $\mathrm{VDD}^{(1)}$, although vitamin D supplementation (e.g. $>1000 \mathrm{IU} / \mathrm{d}$ ) does not always decrease PTH concentrations and the inverse vitamin D-PTH relationship is not strictly linear. Potential factors that may cause lower $25(\mathrm{OH}) \mathrm{D}$ concentrations include skin colour, BMI, season, region, vitamin supplements and others ${ }^{(5)}$.

Vitamin D has been traditionally associated with skeletal health, and VDD leads to rickets in children and osteomalacia and osteoporosis in adults ${ }^{(1)}$. However, accumulating evidence reveals that vitamin D has beneficial effects on optimal function of extraskeletal organs and tissues throughout the human body $^{(1,3,4)}$. VDD has been linked to the increased risk of cardiovascular events ${ }^{(6-8)}$. Higher vitamin D concentrations are associated with reduced cancer incidence and decreased cancer-related mortality ${ }^{(9-11)}$. Furthermore, VDD has also been linked to the development of hypertension ${ }^{(12)}$, type I diabetes $^{(13)}$, multiple sclerosis ${ }^{(14)}$, rheumatoid arthritis ${ }^{(15)}$ and other autoimmune conditions ${ }^{(16)}$.

In the past few years, reports of VDD have increased in nonequatorial locations worldwide ${ }^{(17-20)}$. Although comparisons among studies are difficult because of diversity of the populations and controversy about what cut-offs should be used ${ }^{(21,22)}$, it is clear that blood $25(\mathrm{OH}) \mathrm{D}$ concentrations are often below recommended ranges for the general population ${ }^{(17,23)}$. VDD has

Abbreviations: 25(OH)D, 25-hydroxyvitamin D; IOM, Institute of Medicine; NHANES, National Health and Nutrition Examination Survey; PTH, parathyroid hormone; VDD, vitamin D deficiency; VDI, vitamin D insufficiency.

* Corresponding author: X. Liu, fax +1 734647 2416, email liuxf@med.umich.edu 
been investigated in infants and toddlers, healthy adolescents, obese children and African Americans ${ }^{(24-27)}$, yet limited information is available on the prevalence and predictors of VDD and vitamin D insufficiency (VDI) among US adults. Several studies have reported vitamin D status and changes in serum $25(\mathrm{OH}) \mathrm{D}$ concentrations in the general US population ${ }^{(28,29)}$. However, they have used conservative cut-offs for the definitions of VDD $(25(\mathrm{OH}) \mathrm{D}<30 \mathrm{nmol} / 1 \text { or even lower })^{(21,25)}$, which may not be clinically informative, and have focused on mean $25(\mathrm{OH}) \mathrm{D}$ concentrations, instead of VDD prevalence ${ }^{(29)}$.

It is of public health importance to evaluate VDD and VDI status defined by clinically adopted criteria, and to identify groups at high risk of VDD and VDI along with factors associated with these conditions among US adults in a large nationally representative population. Although the Institute of Medicine (IOM) recommended a threshold of $50 \mathrm{nmol} / \mathrm{l}$ for bone health, recent studies have shown that a threshold of $50 \mathrm{nmol} / \mathrm{l}(20 \mathrm{ng} / \mathrm{ml})$ is insufficient for fracture or fall reduction, and bone density increases with higher 25(OH)D concentrations far beyond $50 \mathrm{nmol} / \mathrm{l}(20 \mathrm{ng} / \mathrm{ml})$ in adults, suggesting that the IOM threshold recommendation may be too low for optimal bone health in adults ${ }^{(30,31)}$. Accordingly, we adopted the criteria recommended by the Endocrinology Society to define VDD $(25(\mathrm{OH}) \mathrm{D}<50 \mathrm{nmol} / \mathrm{l})$ and VDI $(50 \leq 25(\mathrm{OH}) \mathrm{D}<75 \mathrm{nmol} / \mathrm{l})$. The objectives of the study were to examine the prevalence in the subgroups defined by age, sex, race/ethnicity and other variables, and to identify socio-demographic, behavioural and dietary factors associated with a higher prevalence of VDD and VDI using data from the National Health and Nutrition Examination Survey (NHANES).

\section{Methods \\ Study sample}

The continuous NHANES is designed to assess the health and nutrition status among children and adults in the US civilian non-institutionalised population. It includes a series of 2-year cross-sectional surveys conducted by the National Center for Health Statistics (NCHS) in the Center for Disease Control and Prevention $(\mathrm{CDC})^{(32)}$. NHANES participants are selected through the use of stratified multi-stage clustered probability sampling design. The surveys integrate interview and examination components. Face-to-face interviews were performed at the volunteer's house to collect demographic, socio-economic, dietary and health-related information. Examinations are conducted in the mobile examination centres to obtain medical, physiological and laboratory measurements. All adults provided written informed consent, and the study was approved by the NCHS Institutional/Ethics Review Board. The detailed information has been described in the NHANES website and the previous studies $^{(32,33)}$.

Vitamin D data were selected from the continuous NHANES 2001-2010 for this study. A total of 64994 individuals were screened in 2001-2010. Among them, 52195 (80.3\%) participated in the interview and $50085(77 \cdot 1 \%)$ were involved in the examination. The individuals aged $<18$ years, who participated in interview or examination but not both and who had missing values on $25(\mathrm{OH}) \mathrm{D}$ concentration were excluded from the present study. After these exclusions, a final sample of 26010 subjects with complete data on 25(OH)D were included for further analysis. We removed missing measurements from the study for two considerations: (1) the included data without missing values were quite large and could ensure the analysis power to detect the significance difference; and (2) excluded missing values could be reasonably thought to have no significant impact on the final results because there were no significant differences in characteristics between included data and excluded missing data.

\section{Assessment of vitamin D deficiency and insufficiency}

VDD and VDI were determined based on the serum 25(OH)D concentration that was measured at the Division of Laboratory Sciences in the CDC National Center for Environmental Health. In 2007-2010, serum 25(OH)D metabolites were assayed using a standardised liquid chromatography-tandem MS (LC-MS/MS) method traceable to the National Institute of Standards and Technology reference materials ${ }^{(34,35)}$. The total concentrations of serum $25(\mathrm{OH}) \mathrm{D}$ were calculated as the sum of $25(\mathrm{OH}) \mathrm{D}_{2}$ and 25 $(\mathrm{OH}) \mathrm{D}_{3}$. For 2001-2006, total 25(OH)D concentrations were initially measured using a DiaSorin RIA kit. Because of the concern about imprecision and bias in the method, RIA measurements of 25(OH)D concentration in 2001-2006 were adjusted for assay drifts and converted to LC-MS/MS method equivalent measurements ${ }^{(34)}$. (For details on vitamin $\mathrm{D}$ adjustment from survey to survey, see the online Supplementary materials.) This standardisation was conducted so that we could use the LC-MS/MS-equivalent data for NHANES 2001-2006 to compare with 25(OH)D data from NHANES 2007-2010. VDD and VDI were determined from the standardised $25(\mathrm{OH}) \mathrm{D}$ data. For purposes of this analysis, a participant was defined as VDD if his/ her concentration of serum $25(\mathrm{OH}) \mathrm{D}$ was $<50 \mathrm{nmol} / \mathrm{l}$, and VDI if the serum $25(\mathrm{OH}) \mathrm{D}$ concentration was $\geq 50$ and $<75 \mathrm{nmol} / \mathrm{l}$.

\section{Socio-demographic, behavioural and dietary factors}

Factors that have potential to cause lower $25(\mathrm{OH}) \mathrm{D}$ concentrations were chosen according to the previous studies ${ }^{(5,36)}$. Participants were classified into three groups in terms of age: young adults (18-39 years), middle-aged adults (40-59 years) and old adults (60 year or above). Race/ethnicity was determined by self-report and included non-Hispanic white, nonHispanic black, Hispanic and other race (combined from American Indian, Alaskan Native, Asian or Pacific Islander and other race not specified for sufficient number of individuals and meaningful analyses). Education levels were categorised as high school or below and college or above in terms of years in school. The family's poverty income ratio was calculated by dividing total family income by the poverty threshold, which was a guideline specific to family size, as well as the appropriate year and state, as issued annually by the Department of Health and Human Services.

Participant's standing height was measured by a fixed stadiometer and body weight was taken on a Toledo digital scale. BMI was calculated as weight in $\mathrm{kg}$ divided by the square of height in $\mathrm{m}$. A participant was determined to have obesity if 
BMI $\geq 30 \mathrm{~kg} / \mathrm{m}^{2}$. History of smoking was obtained from household interview for participants aged $\geq 20$ years and from the examination centre for participants aged 18-19 years. Smokers were defined as subjects aged $\geq 20$ years who smoked $\geq 100$ cigarettes in their lives or subjects aged 18-19 years who had ever tried smoking a whole cigarette. Current smokers included those smokers aged $\geq 20$ years who reported current smoking and those aged 18-19 years who reported smoking in the past $5 \mathrm{~d}$; former smokers included smokers who did not report current smoking. Alcohol use was determined by response to the question 'Had at least 12 alcohol drinks per year?'.

Milk in the USA is routinely fortified with vitamin D, and therefore it is an important source of vitamin $\mathrm{D}^{(37)}$. Participant's milk consumption was obtained from the diet, behaviour and nutrition data of the Questionnaire and was categorised as rarely (less than once a week or never), sometimes (more than once a week but less than daily) and frequent (once a day or more). In terms of the time period when the examination was performed, participating season was categorised into winter (sampled on 1 November to 30 April) and summer (sampled on 1 May to 31 October). Information for physical activity was collected from the NHANES Sample Person Questionnaire 2001-2010. Physical inactivity was defined as not participating in either vigorous or moderate-intensity exercises in the past $30 \mathrm{~d}$ before the interview.

\section{Statistical analysis}

The NHANES uses a complex stratified multi-stage sampling design to select participants. We performed survey procedures to account for the complex design, estimate mean values and percentages and provide $95 \%$ CI by considering strata, cluster and sampling techniques. The NHANES Analytic and Reporting Guidelines 20012010 were followed for the data analysis ${ }^{(32)}$. Standard errors were estimated with Taylor series linearisation. Sampling weights were recalculated to extend the results to the general US population by dividing 2-year sampling weights from each cycle of the NHANES by the number of cycles we used in the study.

We calculated means with $95 \%$ CI for continuous variables and percentages/rates with $95 \%$ CI for categorical variables. The Wald $F$ test was used to compare means of continuous variables and the $\chi^{2}$ test was used to compare percentages of categorical variables for the significance of difference in means or percentages/rates over vitamin D status. The prevalences of VDD and VDI were estimated, respectively, by dividing the weighted frequency of VDD and the weighted frequency of VDI by the weighted total population represented by the study sample. The prevalence estimates with 95\% CI were derived from survey frequency procedures. Prevalence ratios (PR) and 95\% CI were estimated by conducting weighted log-Binomial regression models, and were used to reflect the associations of socio-demographic (age, sex, race/ethnicity, education and family income ratio), behavioural (obesity status, smoking, alcohol use and physical activity) and dietary (milk drinking) factors with the prevalences of VDD and VDI. The Wald $\chi^{2}$ test was used to determine the $P$ value and the significance of associations. Weighted multiple linear regression models were conducted to examine the associations of the above factors with the concentration of $25(\mathrm{OH}) \mathrm{D}$. Three basic assumptions were checked using q-q plot for normality and residual plots for independence and equal variances. All the analyses were performed using SAS statistical software (SAS version 9.4; SAS Institute Inc.).

\section{Results}

A total of 26010 subjects aged $\geq 18$ years were included in the study sample. They represented 199487260 non-institutionalised adults in the USA. Average age of the study population was 45.6 years. Females were $51.7 \%$, non-Hispanic blacks were $10.7 \%$ and Hispanics were $12.7 \%$. Current smoking rate was $30.1 \%$ and current drinking rate was $74.2 \%$ (Table 1 ). Among adults aged $\geq 18$ years, the prevalence of VDD $(25(\mathrm{OH}) \mathrm{D}<50 \mathrm{nmol} / \mathrm{l})$ was 28.9 (SE 1.01$) \%$ and the prevalence of VDI $(50 \leq 25(\mathrm{OH}) \mathrm{D}<75$ $\mathrm{nmol} / \mathrm{l}$ ) was 41.4 (SE 0.63$) \%$. The prevalences of VDD and VDI did not change significantly over time during 2001-2010 $(P=0 \cdot 18$ for linear trend of VDD; $P=0 \cdot 15$ for linear trend of VDI) (Fig. 1). Additional analysis showed that (1) the prevalence of $25(\mathrm{OH}) \mathrm{D}$ $<30 \mathrm{nmol} / \mathrm{l}$ was 6.4 (se 0.40 ) \%, and did not change over time (Fig. 2 ), and that (2) the percentage of participants with $25(\mathrm{OH})$ $\mathrm{D}>125 \mathrm{nmol} / \mathrm{l}$ was $1.7 \%$ and that with $25(\mathrm{OH}) \mathrm{D}>150 \mathrm{nmol} / \mathrm{l}$ was $0.38 \%$ (high levels considered by IOM (North America) and the European Food Safety Authority (Europe) to have potential adverse effects on health).

Adults with VDD ( $v$. normal vitamin D) were more likely to be poor, less educated, non-Hispanic black and Hispanic, obese, physically inactive and infrequent to consume milk (Table 1). However, adults with VDD were less likely to be current alcohol drinkers or former smokers. Adults who had VDI ( $v$. normal vitamin D) were more likely to be poor, non-Hispanic black and Hispanic, obese and inactive, but were less likely to be women and current alcohol drinkers.

Prevalence estimates of VDD and VDI among US adults in NHANES 2001-2010 are presented in Table 2. From this table, we can see that non-Hispanic blacks had the highest prevalence of VDD (71.9\%) among racial groups. The prevalence of VDD was higher in adults who received high school education or below compared with those with college education or above $(35.0 v \cdot 27.5 \%)$, and higher in poor v. non-poor adults ( 40.5 v. 26.8\%). Adults who were obese, current smokers, sampled in the winter, physically inactive and rare consumers of milk had higher prevalence of VDD than those who were non-obese (38.5 v. 24.0\%), former smokers (31.9 v. 22.8\%), sampled in the summer $(39 \cdot 3 v .22 \cdot 1 \%)$, active (38.9 v. $24.3 \%)$ and frequent consumers of milk (38.0 v. 21.0\%), respectively. Current alcohol drinkers had lower prevalence of VDD compared with non-drinkers (25.3 v. 36.8\%).

Table 3 lists adjusted PR with 95\% CI of VDD and VDI associated with socio-demographic, behavioural and dietary factors in NHANES 2001-2006. After adjustment for other potential factors, old adults were $63 \%$ more likely to have VDD and $46 \%$ more likely to have VDI than young adults. Among the independent predictors, being a minority was the strongest indicator for VDD and VDI; compared with non-Hispanic whites, non-Hispanic blacks had 24.58 and 3.70 times and Hispanics had 4.30 and 2.33 times higher prevalence of VDD 
Table 1. Characteristics of subjects by vitamin D status among adults $\geq 18$ years in the National Health and Nutrition Examination Survey $2001-2010$ (Mean values and $95 \%$ confidence intervals; percentages)

\begin{tabular}{|c|c|c|c|c|c|c|c|c|c|}
\hline \multirow[b]{2}{*}{ Characteristics } & \multirow[b]{2}{*}{ Count $(n)$} & \multicolumn{2}{|r|}{ All } & \multicolumn{2}{|c|}{$\begin{array}{l}\text { Normal }(25(\mathrm{OH}) \\
\mathrm{D} \geq 75 \mathrm{nmol} / \mathrm{l})\end{array}$} & \multicolumn{2}{|c|}{$\begin{array}{c}\text { Insufficient }(50 \leq 25(\mathrm{OH}) \\
D<75 \mathrm{nmol} / \mathrm{l})\end{array}$} & \multicolumn{2}{|c|}{$\begin{array}{l}\text { Deficient }(25(\mathrm{OH}) \\
\mathrm{D}<50 \mathrm{nmol} / \mathrm{l})\end{array}$} \\
\hline & & Mean & $95 \% \mathrm{Cl}$ & Mean/percentage & $95 \% \mathrm{Cl}$ & Mean/percentage & $95 \% \mathrm{Cl}$ & Mean/percentage & $95 \% \mathrm{Cl}$ \\
\hline Count $(n)$ & & \multicolumn{2}{|c|}{26010} & \multicolumn{2}{|l|}{6199} & \multicolumn{2}{|l|}{10047} & \multicolumn{2}{|l|}{9764} \\
\hline \multicolumn{10}{|l|}{ Age (years) } \\
\hline Mean & 26010 & $45 \cdot 6$ & $45 \cdot 1,46 \cdot 2$ & $46 \cdot 2$ & $45 \cdot 5,47 \cdot 0$ & $45 \cdot 9$ & $45 \cdot 3,46 \cdot 5$ & $44 \cdot 7^{\star}$ & $44 \cdot 0,45 \cdot 3$ \\
\hline $18-39(\%)$ & 10343 & 39.9 & $38 \cdot 6,41 \cdot 1$ & $38 \cdot 7$ & $36 \cdot 8,40 \cdot 5$ & $39 \cdot 0$ & $37 \cdot 3,40 \cdot 7$ & $42 \cdot 4^{\star}$ & $40 \cdot 8,44 \cdot 1$ \\
\hline $40-59(\%)$ & 7485 & $37 \cdot 7$ & $36 \cdot 7,38 \cdot 6$ & $37 \cdot 6$ & $36 \cdot 1,39 \cdot 1$ & 38.5 & $36 \cdot 9,40 \cdot 1$ & $36 \cdot 6^{*}$ & $35 \cdot 1,38 \cdot 0$ \\
\hline$\geq 60(\%)$ & 8182 & $22 \cdot 4$ & $21 \cdot 4,23.5$ & 23.7 & $22 \cdot 2,25 \cdot 3$ & $22 \cdot 5$ & $21 \cdot 1,23 \cdot 8$ & $21 \cdot 0^{*}$ & $19 \cdot 4,22 \cdot 6$ \\
\hline \multicolumn{10}{|l|}{ Sex } \\
\hline Women (\%) & 13400 & 51.7 & $51 \cdot 2,52 \cdot 3$ & $54 \cdot 7$ & $53 \cdot 2,56 \cdot 2$ & $46 \cdot 8$ & $45 \cdot 6,48 \cdot 1$ & $55 \cdot 6^{*}$ & $54 \cdot 3,56 \cdot 8$ \\
\hline \multicolumn{10}{|l|}{ Race/ethnicity } \\
\hline Non-Hispanic white (\%) & 12770 & $71 \cdot 1$ & $68.3,73.9$ & $89 \cdot 6$ & $87 \cdot 8,91.4$ & $75 \cdot 4$ & $72 \cdot 8,78 \cdot 0$ & $45 \cdot 8^{*}$ & $41 \cdot 9,49 \cdot 7$ \\
\hline Non-Hispanic black (\%) & 6968 & $10 \cdot 7$ & $9 \cdot 3,12 \cdot 2$ & $2 \cdot 0$ & $1.5,2.4$ & $5 \cdot 9$ & $4.9,6 \cdot 9$ & $26 \cdot 7^{\star}$ & $23 \cdot 6,29 \cdot 8$ \\
\hline Hispanic (\%) & 5164 & $12 \cdot 7$ & $10 \cdot 6,14.7$ & $5 \cdot 7$ & $4 \cdot 2,7 \cdot 2$ & 13.5 & $11 \cdot 3,15 \cdot 6$ & $18 \cdot 7^{\star}$ & $15 \cdot 8,21 \cdot 7$ \\
\hline \multicolumn{10}{|l|}{ Education } \\
\hline High school or below (\%) & 8418 & $44 \cdot 9$ & $43 \cdot 1,46 \cdot 8$ & 41.5 & $38 \cdot 8,44 \cdot 2$ & $42 \cdot 7$ & $40 \cdot 4,45 \cdot 1$ & $50 \cdot 9^{*}$ & $48.5,53 \cdot 3$ \\
\hline \multicolumn{10}{|l|}{ Family poverty income ratio } \\
\hline Mean & 24216 & 3.0 & $2 \cdot 9,3 \cdot 1$ & $3 \cdot 3$ & $3 \cdot 2,3 \cdot 4$ & $3 \cdot 1$ & $3 \cdot 0,3 \cdot 2$ & $2 \cdot 6^{\star}$ & $2 \cdot 5,2 \cdot 7$ \\
\hline Poor (\%) & 5010 & $13 \cdot 6$ & $12 \cdot 7,14 \cdot 6$ & 9.9 & $8 \cdot 8,11 \cdot 1$ & $12 \cdot 4$ & $11 \cdot 2,13 \cdot 6$ & $19 \cdot 3^{*}$ & $18 \cdot 0,20 \cdot 5$ \\
\hline \multicolumn{10}{|l|}{ BMI $\left(\mathrm{kg} / \mathrm{m}^{2}\right)$} \\
\hline Mean & 25449 & $28 \cdot 3$ & $28 \cdot 2,28 \cdot 5$ & $26 \cdot 6$ & $26 \cdot 4,26 \cdot 8$ & $28 \cdot 4$ & $28 \cdot 1,28 \cdot 6$ & $30 \cdot 1^{*}$ & $29 \cdot 9,30 \cdot 4$ \\
\hline Obesity (\%) & 8591 & $32 \cdot 8$ & $31.7,33.8$ & $21 \cdot 7$ & $20 \cdot 4,22.9$ & $33 \cdot 1$ & $31 \cdot 2,35 \cdot 0$ & $43 \cdot 9^{*}$ & $42 \cdot 3,45 \cdot 6$ \\
\hline \multicolumn{10}{|l|}{ Smoking } \\
\hline Former smoking (\%) & 6320 & $24 \cdot 2$ & $23 \cdot 3,25 \cdot 2$ & $27 \cdot 1$ & $25 \cdot 4,28 \cdot 8$ & 25.5 & $24 \cdot 1,26 \cdot 9$ & $19 \cdot 4^{*}$ & $18 \cdot 3,20 \cdot 4$ \\
\hline Current smoking (\%) & 6958 & $30 \cdot 1$ & $28 \cdot 9,31 \cdot 2$ & 28.9 & $27 \cdot 1,30 \cdot 8$ & $28 \cdot 4$ & $27 \cdot 1,29 \cdot 8$ & $33 \cdot 6^{*}$ & $32 \cdot 1,35 \cdot 2$ \\
\hline \multicolumn{10}{|l|}{ Season } \\
\hline Winter time (\%) & 12063 & 39.8 & $34.5,45 \cdot 1$ & $28 \cdot 1$ & $23 \cdot 2,33 \cdot 0$ & $38 \cdot 2$ & $33 \cdot 2,43 \cdot 3$ & $54 \cdot 1^{*}$ & $47 \cdot 4,60 \cdot 8$ \\
\hline \multicolumn{10}{|l|}{ Alcohol use } \\
\hline Current drinking (\%) & 15492 & $74 \cdot 2$ & $72 \cdot 3,76 \cdot 2$ & $80 \cdot 2$ & $77 \cdot 7,82 \cdot 8$ & $75 \cdot 2$ & $72 \cdot 7,77 \cdot 6$ & $66 \cdot 4^{\star}$ & $64 \cdot 6,68 \cdot 3$ \\
\hline \multicolumn{10}{|l|}{ Physical activity } \\
\hline Inactivity (\%) & 9856 & 31.7 & $30.4,32.9$ & 23.0 & $21 \cdot 1,25 \cdot 0$ & $30 \cdot 3$ & $28 \cdot 8,31 \cdot 8$ & $42 \cdot 7^{\star}$ & $41 \cdot 3,44 \cdot 1$ \\
\hline \multicolumn{10}{|l|}{ Milk drinking } \\
\hline Rarely (\%) & 7508 & $28 \cdot 5$ & $27 \cdot 6,29.5$ & $23 \cdot 8$ & $22 \cdot 4,25 \cdot 2$ & 25.7 & $24 \cdot 4,27 \cdot 0$ & $37 \cdot 5^{\star}$ & $36 \cdot 1,38 \cdot 8$ \\
\hline Sometimes (\%) & 7015 & $27 \cdot 3$ & $26 \cdot 5,28 \cdot 1$ & 24.4 & $23 \cdot 2,25 \cdot 7$ & $27 \cdot 1$ & $25 \cdot 8,28 \cdot 4$ & $30 \cdot 5^{\star}$ & $29 \cdot 3,31 \cdot 8$ \\
\hline
\end{tabular}

25(OH)D, 25-hydroxyvitamin D.

${ }^{\star} P<0.001$ for the significance of overall difference in means or percentages of characteristics across vitamin $D$ groups.

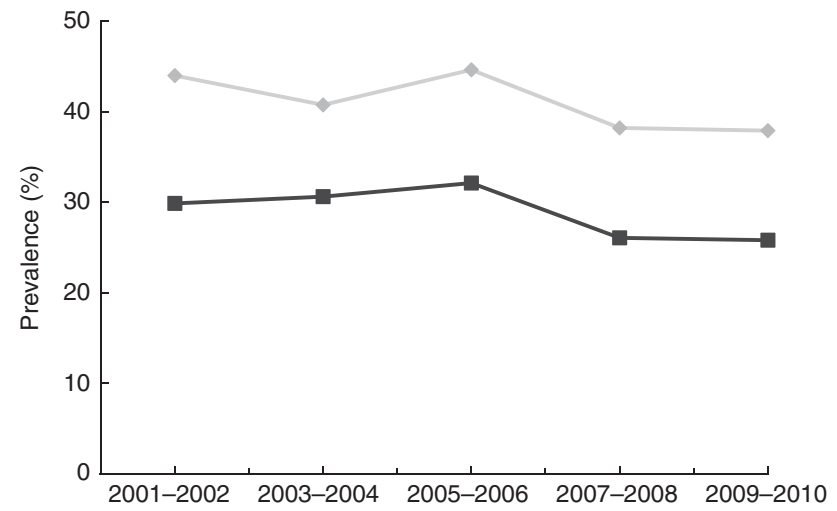

Fig. 1. Trends in the prevalence of vitamin $D$ deficiency $(--)$ and insufficiency $(-)$ among adults $\geq 18$ years in the National Health and Nutrition Examination Survey 2001-2010 (vitamin D deficiency was defined as 25-hydroxyvitamin $D(25(\mathrm{OH}) \mathrm{D})<50 \mathrm{nmol} / \mathrm{l}$ and vitamin $\mathrm{D}$ insufficiency was defined as $50 \leq 25(\mathrm{OH}) \mathrm{D}<75 \mathrm{nmol} / \mathrm{l})$.

and VDI, respectively. Obese adults had 3.09 times higher prevalence of VDD and 1.88 times higher prevalence of VDI than non-obese adults. Adults had 2.42 times higher prevalence of VDD and 1.46 times higher prevalence of VDI in winter than

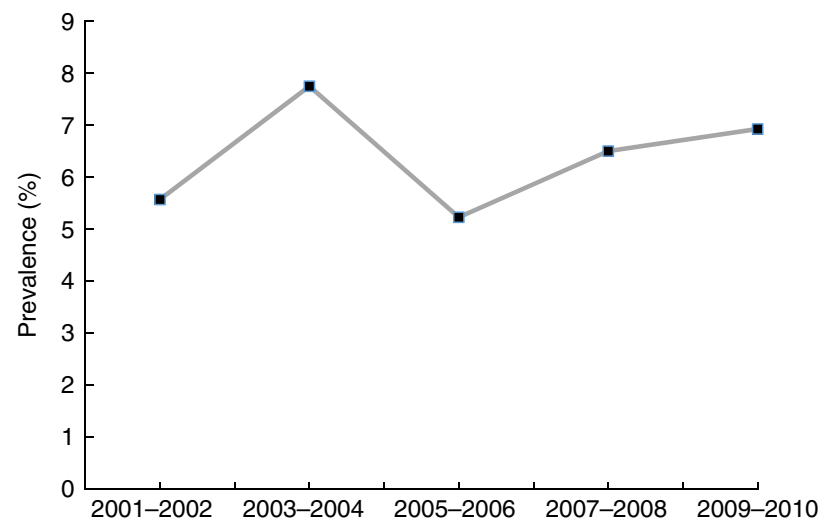

Fig. 2. Trends in the prevalence of 25 -hydroxyvitamin $D(25(\mathrm{OH}) \mathrm{D})<30 \mathrm{nmol} / \mathrm{l}$ among adults $\geq 18$ years in the National Health and Nutrition Examination Survey 2001-2010.

in summer. Physically inactive adults showed 2.00 and 1.36 times higher prevalences of VDD and VDI than active peers. Rare consumption of milk was associated with 2.44 and 1.25 times higher prevalences of VDD and VDI, and consuming milk sometimes was associated with 83 and 19\% higher prevalence. Current smokers had $26 \%$ higher prevalence than 
Table 2. Prevalence estimates of vitamin $D$ deficiency and insufficiency among adults $\geq 18$ years in the National Health and Nutrition Examination Survey 2001-2010

(Prevalence estimates and 95\% confidence intervals)

\begin{tabular}{|c|c|c|c|c|c|c|c|}
\hline \multirow[b]{2}{*}{ Characteristics } & \multicolumn{3}{|c|}{ Insufficiency $(50 \leq 25(\mathrm{OH}) \mathrm{D}<75 \mathrm{nmol} / \mathrm{l})$} & \multicolumn{3}{|c|}{ Deficiency $(25(\mathrm{OH}) \mathrm{D}<50 \mathrm{nmol} / \mathrm{l})$} & \multirow[b]{2}{*}{$P$} \\
\hline & Prevalence & $95 \% \mathrm{Cl}$ & Count $(n)$ & Prevalence & $95 \% \mathrm{Cl}$ & Count $(n)$ & \\
\hline \multicolumn{8}{|l|}{ Age (years) } \\
\hline $18-39$ & $40 \cdot 2$ & $38 \cdot 6,41 \cdot 8$ & 3785 & $30 \cdot 8$ & $28 \cdot 3,33 \cdot 2$ & 4200 & \multirow[t]{3}{*}{0.0016} \\
\hline $40-59$ & $42 \cdot 0$ & $40 \cdot 1,43 \cdot 9$ & 2974 & 28.1 & $25 \cdot 7,30 \cdot 4$ & 2811 & \\
\hline$\geq 60$ & 41.2 & $39 \cdot 8,42,6$ & 3288 & $27 \cdot 1$ & $25 \cdot 4,28 \cdot 8$ & 2753 & \\
\hline \multicolumn{8}{|l|}{ Sex } \\
\hline Men & $45 \cdot 3$ & $43 \cdot 7,46 \cdot 8$ & 5343 & $26 \cdot 6$ & $24 \cdot 5,28 \cdot 7$ & 4460 & \multirow[t]{2}{*}{0.0001} \\
\hline Women & $37 \cdot 2$ & $35 \cdot 7,38.7$ & 4704 & $31 \cdot 1$ & $29 \cdot 0,33 \cdot 2$ & 5304 & \\
\hline \multicolumn{8}{|l|}{ Race/ethnicity } \\
\hline Non-Hispanic white & $43 \cdot 6$ & $42 \cdot 3,44 \cdot 9$ & 5485 & $18 \cdot 6$ & $17 \cdot 0,20 \cdot 3$ & 2494 & \multirow[t]{4}{*}{$<0.0001$} \\
\hline Non-Hispanic black & $22 \cdot 6$ & $20 \cdot 2,25 \cdot 0$ & 1179 & 71.9 & $68.9,74.9$ & 3680 & \\
\hline Hispanic & 43.7 & $41.5,45 \cdot 9$ & 2951 & $42 \cdot 8$ & $39 \cdot 4,46 \cdot 1$ & 3081 & \\
\hline Other race & $38 \cdot 8$ & $35 \cdot 1,42 \cdot 4$ & 432 & $46 \cdot 1$ & $41 \cdot 8,50.5$ & 509 & \\
\hline \multicolumn{8}{|l|}{ Education } \\
\hline High school or below & $41 \cdot 0$ & $38 \cdot 8,43 \cdot 3$ & 3208 & $35 \cdot 0$ & $31 \cdot 6,38 \cdot 4$ & 3723 & \multirow[t]{2}{*}{$<0.0001$} \\
\hline College or above & $44 \cdot 8$ & $42 \cdot 8,46 \cdot 9$ & 2759 & 27.5 & $24.8,30 \cdot 3$ & 2369 & \\
\hline \multicolumn{8}{|l|}{ Poverty status } \\
\hline Non-poor & $41 \cdot 8$ & $40 \cdot 6,43 \cdot 1$ & 7524 & $26 \cdot 8$ & $24 \cdot 9,28 \cdot 7$ & 6753 & \multirow[t]{2}{*}{$<0.0001$} \\
\hline Poor & 37.6 & $35 \cdot 0,40 \cdot 1$ & 1832 & 40.5 & $37 \cdot 1,43 \cdot 9$ & 2285 & \\
\hline \multicolumn{8}{|l|}{ Obesity status } \\
\hline Non-obese & $41 \cdot 0$ & $39 \cdot 6,42 \cdot 3$ & 6657 & $24 \cdot 0$ & $22 \cdot 0,25 \cdot 9$ & 5488 & \multirow[t]{2}{*}{$<0.0001$} \\
\hline Obese & 41.6 & $39.4,43.8$ & 3194 & 38.5 & $35 \cdot 9,41 \cdot 0$ & 4009 & \\
\hline \multicolumn{8}{|l|}{ Smoking } \\
\hline Non-smoking & 41.5 & $39 \cdot 8,43 \cdot 2$ & 4448 & $29 \cdot 3$ & $27 \cdot 2,31 \cdot 5$ & 4429 & \multirow[t]{3}{*}{$<0.0001$} \\
\hline Former smoking & 43.4 & $41 \cdot 7,45 \cdot 1$ & 2602 & $22 \cdot 8$ & $20 \cdot 9,24 \cdot 7$ & 1967 & \\
\hline Current smoking & 39.0 & $37 \cdot 1,40 \cdot 8$ & 2570 & 31.9 & $29 \cdot 2,34 \cdot 6$ & 2818 & \\
\hline \multicolumn{8}{|l|}{ Alcohol use } \\
\hline Non-drinking & $40 \cdot 0$ & $37 \cdot 7,42 \cdot 3$ & 2503 & $36 \cdot 8$ & $33.6,40.0$ & 2812 & \multirow[t]{2}{*}{$<0.0001$} \\
\hline Current drinking & $42 \cdot 1$ & $40 \cdot 7,43 \cdot 5$ & 6238 & $25 \cdot 3$ & $23 \cdot 3,27 \cdot 3$ & 5091 & \\
\hline \multicolumn{8}{|l|}{ Season } \\
\hline Summer & $42 \cdot 2$ & $40 \cdot 6,43 \cdot 7$ & 5622 & $22 \cdot 1$ & $20 \cdot 0,24 \cdot 2$ & 4088 & \multirow[t]{2}{*}{$<0.0001$} \\
\hline Winter & 39.5 & $37 \cdot 7,41 \cdot 3$ & 4425 & $39 \cdot 3$ & $36 \cdot 6,42 \cdot 0$ & 5676 & \\
\hline \multicolumn{8}{|l|}{ Physical activity } \\
\hline Inactive & $39 \cdot 3$ & $37 \cdot 4,41 \cdot 1$ & 3642 & 38.9 & $36 \cdot 5,41 \cdot 4$ & 4423 & \multirow[t]{2}{*}{$<0.0001$} \\
\hline Active & $42 \cdot 0$ & $40 \cdot 7,43 \cdot 2$ & 6402 & $24 \cdot 3$ & $22 \cdot 4,26 \cdot 2$ & 5338 & \\
\hline \multicolumn{8}{|l|}{ Milk drinking } \\
\hline Rarely & $37 \cdot 0$ & $35 \cdot 3,38 \cdot 7$ & 2513 & $38 \cdot 0$ & $35 \cdot 4,40 \cdot 6$ & 3609 & $<0.0001$ \\
\hline Sometimes & $40 \cdot 8$ & $38 \cdot 8,42 \cdot 8$ & 2614 & $32 \cdot 3$ & $30.0,34.6$ & 2957 & \\
\hline Often & 43.9 & $42 \cdot 5,45 \cdot 3$ & 4919 & 21.0 & $19 \cdot 2,22 \cdot 8$ & 3196 & \\
\hline
\end{tabular}

25(OH)D, 25-hydroxyvitamin D.

never-smokers. However, current alcohol drinkers had $38 \%$ lower prevalence of VDD compared with non-drinkers.

Associations of characteristics with continuous serum $25(\mathrm{OH})$ D concentration are presented in Table 4. Serum $25(\mathrm{OH}) \mathrm{D}$ concentration was $3.7 \mathrm{nmol} / 1$ lower in old compared with young adults. Non-Hispanic blacks and Hispanics had serum $25(\mathrm{OH}) \mathrm{D}$ concentrations 22.5 and $9.9 \mathrm{nmol} / \mathrm{l}$ lower than nonHispanic whites. Obese adults had 25(OH)D concentration $8 \mathrm{nmol} / \mathrm{l}$ lower than non-obese peers. Average 25(OH)D dropped by $5.7 \mathrm{nmol} / 1$ in winter compared with summer. Physical inactivity and infrequent milk consumption reduced serum 25(OH)D concentration by 4.8 and $6.2 \mathrm{nmol} / 1$, respectively. However, current alcohol drinking increased serum $25(\mathrm{OH}) \mathrm{D}$ concentration by $3.1 \mathrm{nmol} / \mathrm{l}$.

\section{Discussion}

Using the NHANES as a representative sample of the US population, we found that the national prevalences of VDD and VDI were 28.9 and $41.4 \%$, respectively. This reflects a remarkable degree of deficient or insufficient vitamin D stores among US adults, as the overall prevalence of $25(\mathrm{OH}) \mathrm{D}<75 \mathrm{nmol} / 1$ accounted for $70.3 \%$ of the civilian non-institutionalised adult population. Although we have recognised that the IOM report and the recent UK Scientific Advisory Committee on Nutrition report define VDD as a $25(\mathrm{OH}) \mathrm{D}$ concentration $<30$ and $25 \mathrm{nmol} / \mathrm{l}$, respectively, we adopted the criteria recommended by the Endocrinology Society to define VDD $(25(\mathrm{OH}) \mathrm{D}<50$ $\mathrm{nmol} / \mathrm{l}$ ) in the present study because this cut-off is the point where PTH starts to rise, which is the physiological definition of VDD. Different cut-offs, diversity of the populations and seasonality may have affected the prevalence estimates of VDD and VDI from study to study. Using standardised information from 55844 Europeans, Cashman et al. ${ }^{(17)}$ reported that $40 \%$ of individuals had $25(\mathrm{OH}) \mathrm{D}$ concentrations $<50 \mathrm{nmol} / 1$, regardless of age group, ethnicity and latitude of study populations. Despite geographic differences, this is consistent with data from the last wave of the Mexican Health and Aging Study, showing 
Table 3. Adjusted prevalence ratios of vitamin D deficiency and insufficiency associated with characteristics among adults $\geq 18$ years in the National Health and Nutrition Examination Survey 2001-2010

(Adjusted prevalence ratios and $95 \%$ confidence intervals)

\begin{tabular}{|c|c|c|c|c|c|c|}
\hline \multirow[b]{2}{*}{ Characteristics } & \multicolumn{3}{|c|}{ Insufficiency $(50 \leq 25(\mathrm{OH}) \mathrm{D}<75 \mathrm{nmol} / \mathrm{l})(v . \geq 75 \mathrm{nmol} / \mathrm{l})$} & \multicolumn{3}{|c|}{ Deficiency $(25(\mathrm{OH}) \mathrm{D}<50 \mathrm{nmol} / \mathrm{l})(v . \geq 75 \mathrm{nmol} / \mathrm{l})$} \\
\hline & Prevalence ratios & $95 \% \mathrm{Cl}$ & $P$ & Prevalence ratios & $95 \% \mathrm{Cl}$ & $P$ \\
\hline \multicolumn{7}{|l|}{ Age (v. 18-39 years) } \\
\hline $40-59$ years & $1 \cdot 19$ & $0.99,1.41$ & 0.053 & 1.13 & $0.95,1.35$ & 0.16 \\
\hline$\geq 60$ years & 1.46 & $1.24,1.72$ & $<0.0001$ & 1.63 & $1 \cdot 30,2 \cdot 04$ & $<0.0001$ \\
\hline \multicolumn{7}{|l|}{ Sex (v. men) } \\
\hline Women & 0.76 & $0.66,0.89$ & 0.0003 & 1.01 & $0.87,1.19$ & 0.86 \\
\hline \multicolumn{7}{|c|}{ Race/ethnicity ( $v$. non-Hispanic white) } \\
\hline Non-Hispanic black & 3.70 & $2 \cdot 71,5.05$ & $<0.0001$ & 24.58 & $18 \cdot 21,33 \cdot 18$ & $<0.0001$ \\
\hline Hispanic & $2 \cdot 33$ & $1.77,3.08$ & $<0.0001$ & $4 \cdot 30$ & $3 \cdot 04,6 \cdot 10$ & $<0.0001$ \\
\hline Other race & $2 \cdot 22$ & $1.43,3.45$ & 0.0004 & 6.00 & $3.88,9.27$ & $<0.0001$ \\
\hline \multicolumn{7}{|c|}{ Education ( $v$. college or above) } \\
\hline High school or below & 0.88 & $0.78,0.99$ & 0.0328 & 0.87 & $0.76,0.99$ & 0.0373 \\
\hline \multicolumn{7}{|c|}{ Poverty status ( $v$. non-poor) } \\
\hline Poor & 1.04 & $0.86,1.26$ & 0.69 & $1 \cdot 14$ & $0.91,1.44$ & 0.25 \\
\hline \multicolumn{7}{|c|}{ Obesity status ( $v$. non-obese) } \\
\hline Obese & 1.88 & $1.58,2.23$ & $<0.0001$ & 3.09 & $2 \cdot 64,3.62$ & $<0.0001$ \\
\hline \multicolumn{7}{|c|}{ Smoking ( $v$. non-smoking) } \\
\hline Former smoking & 0.86 & $0.72,1.03$ & 0.10 & 0.84 & $0.71,1.00$ & 0.0495 \\
\hline Current smoking & 0.87 & $0.76,1.01$ & 0.07 & $1 \cdot 26$ & $1.07,1.47$ & 0.0044 \\
\hline \multicolumn{7}{|c|}{ Alcohol use ( $v$. non-drinking) } \\
\hline Current drinking & 0.85 & $0.71,1.01$ & 0.06 & 0.62 & $0.49,0.79$ & $<0.0001$ \\
\hline \multicolumn{7}{|l|}{ Season } \\
\hline Winter & 1.46 & $1 \cdot 18,1 \cdot 80$ & 0.0005 & $2 \cdot 42$ & $1 \cdot 81,3 \cdot 23$ & $<0.0001$ \\
\hline \multicolumn{7}{|l|}{ Physical activity ( $v$. active) } \\
\hline Inactive & 1.36 & $1.20,1.53$ & $<0.0001$ & $2 \cdot 00$ & $1 \cdot 74,2 \cdot 30$ & $<0.0001$ \\
\hline \multicolumn{7}{|l|}{ Milk drinking ( $v$. frequent) } \\
\hline Rarely & 1.25 & $1.08,1.46$ & 0.0034 & 2.44 & $2.05,2.91$ & $<0.0001$ \\
\hline Sometimes & $1 \cdot 19$ & $1.02,1.39$ & 0.0283 & 1.83 & $1 \cdot 52,2 \cdot 20$ & $<0.0001$ \\
\hline
\end{tabular}

25(OH)D, 25-hydroxyvitamin D.

Table 4. Association estimates of characteristics with serum 25-hydroxyvitamin $\mathrm{D}(25(\mathrm{OH}) \mathrm{D})$ concentration (nmol/l) among adults $\geq 18$ years in the National Health and Nutrition Examination Survey 2001-2010

(Association estimates and 95\% confidence intervals)

\begin{tabular}{|c|c|c|c|}
\hline Characteristics & Association estimates & $95 \% \mathrm{Cl}$ & $P$ \\
\hline \multicolumn{4}{|l|}{ Age (v. 18-39 years) } \\
\hline $40-59$ years & -1.5 & $-2 \cdot 5,-0.4$ & 0.006 \\
\hline$\geq 60$ years & -3.7 & $-5 \cdot 2,-2 \cdot 2$ & $<0.0001$ \\
\hline \multicolumn{4}{|l|}{$\operatorname{Sex}(v \cdot$ men) } \\
\hline Women & 0.9 & $-0.1,1.9$ & 0.08 \\
\hline \multicolumn{4}{|c|}{ Race/ethnicity ( $v$. non-Hispanic white) } \\
\hline Non-Hispanic black & -22.5 & $-24 \cdot 2,-20 \cdot 8$ & $<0.0001$ \\
\hline Hispanic & -9.9 & $-11.9,-7.7$ & $<0.0001$ \\
\hline Other race & $-13 \cdot 1$ & $-15 \cdot 6,-10 \cdot 6$ & $<0.0001$ \\
\hline \multicolumn{4}{|c|}{ Education ( $v$. college or above) } \\
\hline High school or below & 0.8 & $-0.1,1 \cdot 7$ & 0.08 \\
\hline \multicolumn{4}{|c|}{ Poverty status ( $v$. non-poor) } \\
\hline Poor & $-1 \cdot 1$ & $-2 \cdot 4,0.2$ & 0.09 \\
\hline \multicolumn{4}{|c|}{ Obesity status ( $v$. non-obese) } \\
\hline Obese & $-8 \cdot 0$ & $-9 \cdot 1,-6 \cdot 9$ & $<0.0001$ \\
\hline \multicolumn{4}{|c|}{ Smoking (v. non-smoking) } \\
\hline Former smoking & 0.9 & $-0.3,2 \cdot 2$ & 0.13 \\
\hline Current smoking & -1.3 & $-2.5,0.0$ & 0.051 \\
\hline \multicolumn{4}{|c|}{ Alcohol use ( $v$. non-drinking) } \\
\hline Current drinking & $3 \cdot 1$ & $1.7,4.5$ & $<0.0001$ \\
\hline \multicolumn{4}{|l|}{ Season } \\
\hline Winter & $-5 \cdot 7$ & $-7 \cdot 7,-3 \cdot 7$ & $<0.0001$ \\
\hline \multicolumn{4}{|c|}{ Physical activity ( $v$. active) } \\
\hline Inactive & $-4 \cdot 8$ & $-5 \cdot 7,-4 \cdot 0$ & $<0.0001$ \\
\hline \multicolumn{4}{|l|}{ Milk drinking ( $v$. frequent) } \\
\hline Rarely & $-6 \cdot 2$ & $-7 \cdot 3,-5 \cdot 1$ & $<0.0001$ \\
\hline Sometimes & -3.8 & $-5 \cdot 1,-2 \cdot 4$ & $<0.0001$ \\
\hline
\end{tabular}


that $37 \cdot 3 \%$ Mexican older adults had 25(OH)D concentrations $<50 \mathrm{nmol} / \mathrm{l}^{(18)}$. Clearly, VDD is highly prevalent globally, even in countries with adequate sun exposure.

Using the definition of serum $25(\mathrm{OH}) \mathrm{D}$ concentration $<50 \mathrm{nmol} / \mathrm{l}$, we showed that approximately $72 \%$ of non-Hispanic black adults would be classified as deficient in vitamin D, with other minorities also displaying a higher prevalence of VDD compared with non-Hispanic whites. Higher prevalence of VDD and lower concentration of serum $25(\mathrm{OH}) \mathrm{D}$ among black adults persisted after controlling for other potential predictors (including age, sex, race/ethnicity, education, family income ratio, obesity status, smoking, alcohol use, physical activity and milk drinking). These results were consistent with the findings from previous studies ${ }^{(37-39)}$. Several pathways may explain the difference in the prevalence of VDD across racial/ethnic groups. The higher prevalence in darker-skinned individuals may be due to the melanin pigmentation, which absorbs sunlight, reducing availability of sunlight to trigger natural vitamin $\mathrm{D}$ production $^{(1,37)}$. Lower socio-economic status and worse behavioural and dietary patterns could be another reason for higher prevalence of VDD in minority groups. Our further analysis of racial/ethnic differences in socio-economic, behavioural and other factors reveals that non-Hispanic blacks were less educated, poorer, more obese, more likely to currently smoke, more physically inactive and less likely to frequently drink milk (online Supplementary Table S1). Moreover, lower socioeconomic status including higher rates of poverty and lower education could limit knowledge about healthy diet and lifestyle modification, and hence food choices, particularly non-dairy sources of vitamin D in minority populations ${ }^{(37)}$. This is further confirmed by the finding in the present study that the prevalence of VDD was higher in subjects who were poor and received a high school education or below. Although nonHispanic whites had the lowest prevalence of VDD, they were at greater risk of VDI, suggesting that factors other than skin pigmentation alone contribute to human vitamin D stores. Considering the potential for insufficient-to-deficient transition, non-Hispanic whites should not be considered exempt from concerns about serum 25(OH)D concentrations.

Consistent with prior reports ${ }^{(26,37)}$, we did find that obese adults had a higher prevalence of VDD than those who are nonobese. Obesity-associated VDD is likely due to the decreased bioavailability of vitamin $D_{3}$ from cutaneous and dietary sources because of its deposition in body fat compartments ${ }^{(40)}$. A recent study has shown that a higher BMI leads to lower 25(OH)D rather than the reverse, and effects of lower $25(\mathrm{OH}) \mathrm{D}$ on increasing BMI are likely to be small ${ }^{(41)}$. Therefore, encouraging population-level physical activity to reduce BMI, as recommended by the $\mathrm{CDC}^{(42)}$ and other health agencies, will help decrease the prevalence of VDD. In addition, more outdoor physical activity could also increase $25(\mathrm{OH}) \mathrm{D}$ by more sunlight exposure, which is a major source of vitamin $\mathrm{D}$.

After adjustment for other potential predictors, several behavioural and dietary factors were found to be associated with the prevalences of VDD or VDI, and/or continuous 25(OH)D concentration. Current smoking was linked to an increased prevalence of VDD, which was consistent with a previous report that smokers had significantly reduced concentrations of serum
$25 \mathrm{OHD}^{(43)}$. One possible reason is that nicotine activates a pathway in the brain that suppresses appetite and reduces eating food fortified with vitamin $\mathrm{D}^{(44)}$. Smoking can also decrease production of 1,25 di-hydroxyvitamin $\mathrm{D}$ in lung epithelia and affect 25-hydroxylase activity ${ }^{(45)}$. Whether the number of cigarettes per day or the levels of smoking are differently related to VDD or VDI needs to be further investigated. On the other hand, current alcohol consumption was associated with a decreased prevalence of VDD, which reflects an association between current alcohol use and significantly higher serum 25 $(\mathrm{OH}) \mathrm{D}$ concentration shown in this study. However, the finding stands in contrast to a previous report that linked excessive drinking with low or subnormal concentrations of vitamin $\mathrm{D}^{(46)}$. However, our data lacked information on amount of alcohol use, and hence we could not evaluate a dose-response association of alcohol use with the prevalence of VDD.

Adults with physical inactivity had lower serum 25(OH)D concentration, and were more likely to have VDD and VDI. Obesity status may serve as a mediator for this association, as physical activity plays an important role in weight loss or reduced BMI. Indeed, lower BMI has been associated with reduced prevalences of VDD and VDI in other studies ${ }^{(18,41)}$. Increased physical activity, if outdoors, may also be associated with higher sunlight exposure. Compared with frequent milk consumption, rare or occasional milk consumption was associated with higher prevalences of VDD and VDI and lower serum 25(OH)D concentrations. Milk is fortified with vitamin D in the USA, and is one of the main dietary sources of vitamin D, although the levels of fortification may vary by brand ${ }^{(37)}$.

There were several limitations in this study. The NHANES was a series of surveys with a cross-sectional design, and the association estimates could not be used to reflect causal effects of predictors on VDD and VDI. Single 25(OH)D measurement for each participant in the NHANES may cause misclassification of VDD or VDI, which would affect the association estimates. Further, the biologic effect of $25(\mathrm{OH}) \mathrm{D}$ may not be reliably measured in serum owing to its fat-soluble characteristic. Vitamin D production also varies with geographic latitudes because of the duration and strength of UV rays from sunlight. Unfortunately, region-specific vitamin $\mathrm{D}$ data were not available in the NHANES, nor was specific information on sun exposure, such as time spent outdoors and sunscreen use. Vitamin D supplement use can influence serum vitamin D concentrations, but this factor could not be evaluated owing to the limited information provided in the present study.

In conclusion, the prevalences of VDD and VDI were high, and fewer than $30 \%$ of US adults had sufficient vitamin D for optimal health outcomes. Our data indicate that vitamin D supplementation may be broadly needed perhaps at higher than currently recommended dosages to achieve repletion, particularly for racial and ethnic minorities, as well as for those who are obese, current smokers, physically inactive and infrequent milk consumers. The associations between low vitamin $\mathrm{D}$, physical activity and milk consumption suggest that attention should be paid to increasing opportunities for outdoor exercise (at least $30 \mathrm{~min} / \mathrm{d}$ ) and sun exposure (at least $15 \mathrm{~min} / \mathrm{d}$ ) in leisure time and optimisation of vitamin $\mathrm{D}$ intake, either by diet or supplement. Because vitamin D is linked to skeletal, 
cardiovascular and other organ systems, screening indications and guidelines for supplementation of adults should be evaluated, taking into account latitude and identified influential factors. Health professionals should use these predictors for initiating strategies, both behavioural and dietary, to prevent VDD and monitor VDI, especially for people in old, minority and/or obese groups.

\section{Acknowledgements}

The authors thank the National Center for Health Statistics for the availability of NHANES data.

Research for this study was supported by a Health Resources and Services Administration grant (H2AIT16637).

$\mathrm{X}$. L. designed the study, identified data sources, conducted the data analysis and wrote the first draft of the manuscript; A. B. participated in writing the method section, review of data analysis methods and critical revision of the manuscript; P. D. L. participated in the study design, determination of measurement cut-offs and critical revision of the results and discussion.

The authors declare that there are no conflicts of interest.

\section{Supplementary material}

For supplementary material/s referred to in this article, please visit https://doi.org/10.1017/S0007114518000491

\section{References}

1. Holick MF (2007) Vitamin D deficiency. N Engl J Med 357, 266-281.

2. Trehan N, Afonso L, Levine DL, et al. (2017) Vitamin D deficiency, supplementation, and cardiovascular health. Crit Pathw Cardiol 16, 109-118.

3. Holick MF (2004) Vitamin D: importance in the prevention of cancers, type 1 diabetes, heart disease, and osteoporosis. Am J Clin Nutr 79, 362-371.

4. Lee JH, O'Keefe JH, Bell D, et al. (2008) Vitamin D deficiency: an important, common, and easily treatable cardiovascular risk factor? J Am Coll Cardiol 5, 1949-1956.

5. Hirani V, Mosdol A \& Mishra G (2009) Predictors of 25hydroxyvitamin D status among adults in two British national surveys. Br J Nutr 101, 760-764.

6. Judd SE \& Tangpricha V (2009) Vitamin D deficiency and risk of cardiovascular disease. Am J Med Sci 338, 40-44.

7. Giovannucci E, Liu Y, Hollis BW, et al. (2008) 25-hydroxyvitamin D and risk of myocardial infarction in men: a prospective study. Arch Intern Med 168, 1174-1180.

8. Dobnig H, Pilz S, Scharnagl H, et al. (2008) Independent association of low serum 25-hydroxyvitamin $\mathrm{D}$ and 1,25-dihydroxyvitamin D levels with all-cause and cardiovascular mortality. Arch Intern Med 168, 1340-1349.

9. Freedman DM, Looker AC, Chang SC, et al. (2007) Prospective study of serum vitamin D and cancer mortality in the United States. J Natl Cancer Inst 99, 1594-1602.

10. John EM, Schwartz GG, Dreon DM, et al. (1999) Vitamin D and breast cancer risk: the NHANES I epidemiologic follow-up study, 1971-1975 to 1992: National Health and Nutrition Examination Survey. Cancer Epidemiol Biomarkers Prev 8, 399-406.

11. Zhao XY \& Feldman D (2001) The role of vitamin D in prostate cancer. Steroids 66, 293-300.
12. Rostand SG (1997) Ultraviolet light may contribute to geographic and racial blood pressure differences. Hypertension 30, 150-156.

13. Casteels K, Waer M, Bouillon R, et al. (1998) 1,25-Dihydroxyvitamin $\mathrm{D}_{3}$ restores sensitivity to cyclophosphamide-induced apoptosis in nonobese diabetic (NOD) mice and protects against diabetes. Clin Exp Immunol 112, 181-187.

14. Munger KL, Zhang SM, O'Reilly E, et al. (2004) Vitamin D intake and incidence of multiple sclerosis. Neurology $\mathbf{6 2}$, 60-65.

15. Merlino LA, Curtis J, Mikuls TR, et al. (2004) Vitamin D intake is inversely associated with rheumatoid arthritis: results from the Iowa Women's Health Study. Arthritis Rheum 50, 72-77.

16. Holick MF (2005) Vitamin D: important for prevention of osteoporosis, cardiovascular heart disease, type 1 diabetes, autoimmune diseases, and some cancers. South Med J 98, 1024-1027.

17. Cashman KD, Dowling KG, S`kraba'kova Z, et al. (2016) Vitamin D deficiency in Europe: pandemic? Am J Clin Nutr 103, 1033-1044.

18. Carrillo-Vega MF, García-Peña C, Gutiérrez-Robledo LM, et al. (2017) Vitamin D deficiency in older adults and its associated factors: a cross-sectional analysis of the Mexican Health and Aging Study. Arch Osteoporos 12, 8.

19. Hirani V, Cumming RG, Blyth FM, et al. (2013) Vitamin D status among older community dwelling men living in a sunny country and associations with lifestyle factors: the Concord Health and Ageing in Men Project, Sydney, Australia. J Nutr Health Aging 17, 587-593.

20. Gozdzik A, Barta JL, Wu H, et al. (2008) Low wintertime vitamin $\mathrm{D}$ levels in a sample of healthy young adults of diverse ancestry living in the Toronto area: associations with vitamin D intake and skin pigmentation. BMC Public Health $\mathbf{8}, 336$.

21. Ross AC, Manson JE, Abrams SA, et al. (2011) The 2011 report on dietary reference intakes for calcium and vitamin D from the Institute of Medicine: what clinicians need to know. J Clin Endocrinol Metab 96, 53-58.

22. Holick MF, Binkley NC, Bischoff-Ferrari HA, et al. (2011) Evaluation, treatment, and prevention of vitamin D deficiency: an Endocrine Society clinical practice guideline. J Clin Endocrinol Metab 96, 1911-1930.

23. Holick MF (2008) The vitamin D deficiency pandemic and consequences for nonskeletal health: mechanisms of action. Mol Aspects Med 29, 361-368.

24. Catherine M., Gordon CM, Feldman HA, et al. (2008) Prevalence of vitamin D deficiency among healthy infants and toddlers. Arch Pediatr Adolesc Med 162, 505-512.

25. Gordon CM, DePeter KC, Feldman HA, et al. (2004) Prevalence of vitamin D deficiency among healthy adolescents. Arch Pediatr Adolesc Med 158, 531-537.

26. Turer CB, Lin H \& Flores G (2013) Prevalence of vitamin d deficiency among overweight and obese US children. Pediatrics 131, e152-e161.

27. Freishtat RJ, Iqbal SF, Pillai DK, et al. (2010) High prevalence of vitamin D deficiency among inner-city African American youth with asthma in Washington, DC. J Pediatr 156, 948-952.

28. Looker AC, Johnson CL, Lacher DA, et al. (2011) Vitamin D Status: United States, 2001-2006. NCHS Data Brief, no 59. Hyattsville, MD: National Center for Health Statistics.

29. Looker AC, Pfeiffer CM, Lacher DA, et al. (2008) Serum 25-hydroxyvitamin D status of the US population: 1988-1994 compared with 2000-2004. Am J Clin Nutr 88, 1519-1527.

30. Bischoff-Ferrari HA, Willett WC, Wong JB, et al. (2009) Prevention of nonvertebral fractures with oral vitamin D and dose dependency: a meta-analysis of randomized controlled trials. Arch Intern Med 169, 551-561. 
31. Bischoff-Ferrari HA, Dietrich T, Orav EJ, et al. (2004) Positive association between 25-hydroxy vitamin D levels and bone mineral density: a population-based study of younger and older adults. Am J Med 116, 634-639.

32. National Center for Health Statistics in the Centers for Disease Control and Prevention (2013) National Health and Nutrition Examination Survey. http://www.cdc.gov/nchs/nhanes.htm (accessed February 2013).

33. Liu XF \& Duan FF (2013) Prevalence of isolated systolic hypertension in Mexican Americans and other Hispanics. Am J Hypertens Res 1, 6-12.

34. Schleicher RL, Sternberg MR, Lacher DA, et al. (2016) A methodbridging study for serum 25-hydroxyvitamin D to standardize historical radioimmunoassay data to liquid chromatographytandem mass spectrometry. Natl Health Stat Report 93, 1-16.

35. Al-khalidi1 B, Kimball SM, Rotondi1 MA, et al. (2017) Standardized serum 25-hydroxyvitamin D concentrations are inversely associated with cardiometabolic disease in U.S. adults: a cross-sectional analysis of NHANES, 2001-2010. Nutr J 16, 16.

36. Forrest KYZ \& Stuhldreher WL (2011) Prevalence and correlates of vitamin D deficiency in US adults. Nutr Res 31, 48-54.

37. Calvo MS, Whiting SJ \& Barton CN (2004) Vitamin D fortification in the United States and Canada: current status and data needs. Am J Clin Nutr 80, 1710S-1716S.

38. Zadshir A, Tareen N, Pan D, et al. (2005) The prevalence of hypovitaminosis D among US adults: data from the NHANES III. Ethn Dis 15, Suppl. 5, 97-101.
39. Araujo AB, Travison TG, Esche GR, et al. (2009) Serum 25-hydroxyvitamin $\mathrm{D}$ and bone mineral density among Hispanic men. Osteoporos Int 20, 245-255.

40. Wortsman J, Matsuoka LY, Chen TC, et al. (2000) Decreased bioavailability of vitamin D in obesity. Am J Clin Nutr $\mathbf{7 2}$, 690-693.

41. Vimaleswaran KS, Berry DJ, Liu C, et al. (2013) Causal relationship between obesity and vitamin D status: bi-directional Mendelian randomization analysis of multiple cohorts. PLoS Med 10, e1001383.

42. The Center for Disease Control and Prevention (2014) Physical activity: how much physical activity do adults need? http:// www.cdc.gov/physicalactivity/everyone/guidelines/adults.html (accessed February 2014)

43. Hansdottir S, Monick MM, Lovan N., et al. (2010) Smoking disrupts vitamin D metabolism in the lungs [abstract]. Am J Respir Crit Care Med 181, A1425.

44. Brot C, Jorgensen NR \& Sorensen OH (1999) The influence of smoking on vitamin D status and calcium metabolism. Eur J Clin Nutr 53, 920-926.

45. Jo YH, Talmage DA \& Role LW (2002) Nicotinic receptormediated effects on appetite and food intake. J Neurobiol $\mathbf{5 3}$, 618-632.

46. Wijnia JW, Wielders JPM, Lips P, et al. (2013) Is vitamin D deficiency a confounder in alcoholic skeletal muscle myopathy? Alcohol Clin Exp Res 37, E209-E215. 